\title{
Apolipoprotein-1 (Apol-1) Gene Polymorphism in Hypertensive Nephroscelerosis Egyptian Patients
}

\author{
HASSAN A. AHMED, M.D.*; YASSEIN S. YASSEIN, M.D.*; AHMED M. ZAHRAN, M.D.*; \\ MAHMOUD A. EMARA, M.D.*; RANIA M. AZMY, M.D.** and AZZA A. GOMAH, M.D.* \\ The Departments of Internal Medicine* and Medical Biochemistry**, Faculty of Medicine, Menofia University, Egypt
}

\begin{abstract}
Background: Arterial Hypertension (AHTN) represents a major public health problem for its high frequency among the unselected population and, particularly, for its strong association with cardiovascular morbidity and mortality. Progressive renal disease has always been comprised among the possible end-organ damage-related to hypertension. The APOL1 G1 and G2 risk variants are highly associated with non-diabetic non-HIV associated forms of kidney disease, and in particular FSGS and hypertensive nephropathy.
\end{abstract}

Aim of Study: To study influence of the APOL1 gene variants (G1 and $\mathrm{G} 2$ ) on the hypertensive induced kidney disease among Egyptian Patients.

Subjects and Methods: In the current study, we examined 88 adult patients ( $>! 18$ years old) of both sexes with essential hypertension for $>\mid 5$ years and classified into two groups: Group I: Included fifty-three patients with essential hypertension (B1.Pr. >! 140/90) who have normal kidney function. Group II: Included thirty-five patients with essential hypertension (B1.Pr. >! 140/90) who have impaired kidney function mostly attributed to HTN. Essential hypertension was diagnosed if the patient gave history of hypertension, with antihypertensive medications or if B1.Pr. >! 140/90 at the time of examination without definite cause. All patients were subjected to thorough medical history taking, physical examination, and many investigations were done as well as APOL1 gene study using Polymerase Chain Reaction (PCR).

Results: There is significant statistical difference between both groups as regard APOL1 G1 rs73885319, G1 rs60910195 and $\mathrm{G} 2$ rs71785313 genotypes and alleles (the abnormal genotypes AG, GG, TG, DI, DD are more frequent in patients with hypertensive nephroscelerosis; Group II). Most patients with hypertensive nephroscelerosis (Group II) carry two risk alleles and showed more decline estimated Glomerular Filteration Rate (eGFR) than Group I despite matching in the hypertension duration and severity.

Conclusion: APOL1 G1 rs73885319, G1 rs60910195 and G2 rs71785313 gene polymorphism is associated with increased risk of hypertensive induced kidney disease among Egyptian patients. Most patients with hypertensive nephros-

Correspondence to: Dr. Hassan A. Ahmed, E-Mail: Il ib4e@yahoo.com celerosis (Group II) showed more decline in e-GFR than group I despite matching in the hypertension duration and severity.

Key Words: Hypertensive nephrosclerosis - Apolipoprotein 1 gene.

\section{Introduction}

PROGRESS in reporting the genetic variations characterizing kidney diseases with simple monogenic inheritance (Mendelian disorders) using family based linkage studies over the past two decades has yielded many new insights into kidney disease pathogenesis. These have had immediate clinical diagnostic impact, and have shed light on the key components for functional integrity of the glomerular filtration barrier [1]

The genetics of complex, polygenic kidney diseases, on the other hand, including nonmonogenic forms of chronic kidney disease, has proven more challenging to unravel. Only recently have population genetics approaches, such as $\mathrm{Ge}$ nome-Wide Association Studies (GWAS) and Mapping by Admixture Linkage Disequilibrium (MALD), successfully identified important allelic variants which confer susceptibility to common kidney disease phenotypes, including proteinuria, chronic kidney disease, and hypertension $[2,3]$

Hypertension is a major public health problem affecting $26.3 \%$ of the Egyptians, and only $37.5 \%$ of hypertensive individuals are aware that they have hypertension. Also studies showed that only $8 \%$ of Egyptian hypertensive patients are controlled [4].

This topic of hypertension and renal injury has received growing interest in the last decade mostly due to the data offered by the End-Stage Renal Disease (ESRD) registries. In fact, hypertension as a cause of ESRD has risen progressively and 
more rapidly than all other causes (except diabetes mellitus) in North America and Europe [5]

The mechanism by which the elevated blood pressure can induce pregressive renal failure is not clearly known. Two different hypotheses have been put forward: Renal damage is the result of glomerular ischemia and hypoperfusion due to the narrowing of preglomerular vessels, as it happens in severe renal artery stenosis; or it's the consequence of glomerular capillary hypertension and hyperperfusion due to a loss of the renal autoregulatory response normally present also in the early phase of essential hypertension [6].

The association between Apolipoprotein L 1 gene (APOL1) variants and non-diabetic Chronic Kidney Disease (CKD) has dramatically altered the landscape in nephrology $[\mathbf{7 , 8}]$

It is notable that in recent reports of controlled trials in African-Americans hypertension with kidney disease is associated with the APOL1 risk genotype, and kidney disease deterioration is not ameliorating by more intensive blood pressure control [9].

\section{Subjects and Methods}

Study population: The study was carried out at Internal Medicine Department, Menoufia University Hospital, Egypt during the period from December 2016 to August 2018 following the medical ethical standards of the institution. Informed consents from all patients were obtained in accordance with the Local Medical Ethical Committee.

We examined 88 adult patients ( $\geq 18$ years old) of both sexes with essential hypertension for $\geq 5$ years and classified into two groups:

- Group 1: Fifty-three patients with essential hypertension (B1.Pr. $\geq 140 / 90$ ) who have normal kidney function.

- Group 2: Thirty-five patients with essential hypertension (B1.Pr. $\geq 140 / 90)$ who have impaired kidney function mostly attributed to HTN.

Essential hypertension was diagnosed if the patient gave history of hypertension, with antihypertensive medications or if B1.Pr. $\geq 140 / 90$ at the time of examination without definite cause.

The criteria for the diagnosis of hypertensive nephropathy [10] are as follows: I) Primary hypertension; II) $>5$ years of sustained hypertension before proteinuria; III) Persistent proteinuria (generally mild to moderate) with benign urinary sediment detected by microscopic examination; IV)
Retinal arteriosclerosis or arteriosclerotic changes in the retina; V) Various primary renal diseases are excluded; and VI) Other secondary renal diseases are also excluded. A history of hypertensive left ventricular hypertrophy, coronary heart disease, heart failure, cerebral arteriosclerosis and/or history of cerebral vascular accident, hyperuricemia, renal tubular dysfunction preceding renal function damage, slow progression and other factors are used as auxiliary diagnostic conditions.

\section{Inclusion criteria:}

- Adult patients ( $\geq 18$ years old ) of both sexes.

- Patients with essential hypertension.

- Duration of hypertension $\geq 5$ years.

\section{Exclusion criteria:}

- Causes other than hypertension for renal impairment e.g.: Diabetic patients, obstructive uropath$\mathrm{y}$.... etc.

- Patients with secondary hypertension.

- All the included patients were subjected to:

1- Thorough medical history tacking.

2- Complete physical examination.

3- Routine investigations.

4- Special investigation: Assessment of APOL 1 gene variants by Polymerase Chain Reaction (PCR).

\section{Definitions and calculations:}

Body Mass Index (BMI) was calculated as weight per square meter $\left(\mathrm{kg} / \mathrm{m}^{2}\right)$.

Hypertension was based on a history of doctor diagnosed hypertension and/or receiving medications for hypertension or average systolic blood pressure $\geq 140 \mathrm{mmHg}$ and/or average diastolic blood pressure $\geq 90 \mathrm{mmHg}$.

Urinary albumin excretion was quantified in term of urinary Albumin/Creatinine Ratio (ACR).

Glomerular Filtration Rate (GFR) was estimated by the 4-variable Modification of Diet in Renal Disease (MDRD) equation applicable to standardized serum creatinine values.

MDRD formula:

GFR $=170$ (serum creatinine concentration ${ }^{-0} \cdot 999$ ). $\mathrm{X}$ age ${ }^{-0} .176$

$\mathrm{X} 0.762$ if female

$\mathrm{X} 1.180$ if black

$\mathrm{X}$ blood urea nitrogen concentration ${ }^{-0} \cdot{ }^{17}$

$\mathrm{X}$ serum albumin concentration -0.318 
Assessment of APOL1 gene polymorphisms by $P C R$ and restriction enzymes:

Determination of APOL 1 gene polymorphism (G1 rs73885319, G1 rs60910195 and G2 rs 71785313) by Restriction Fragment Length Polymorphism Polymerase Chain Reaction (RFLP PCR).

A- Sample collection and preparation: Under complete aseptic conditions $2 \mathrm{ml}$ of venous blood were withdrawn from every patient by veinpuncture and transferred into EDTA tube for DNA extraction and PCR.

$B$ - DNA extraction: DNA was extracted from whole blood using Thermo Scientific Gene JET Genomic DNA purification kit from Lithuania. DNA was eluted, stored at $20^{\circ} \mathrm{C}$ for further PCR procedure.

\section{Principle:}

Samples are digested with lysis buffer. The lysate is then mixed and loaded onto the purification column, where the DNA binds to the silica membrane. Impurities are effectively removed by washing the column with wash buffers. Genomic DNA is then eluted under low ionic strength conditions with the elution buffer.

C-Determination of APOL1 gene polymorphism (G1 rs73885319): PCR for APOL1 gene (G1 rs73885319) was carried out to a total volume of 25 , containing 1 Lofforward and 1 reverse primers; $12.5 \mathrm{ul}$ of master mix (genecraft; Germany); (Stratagene; USA) and 0.5ul distal water [11].

APOL1 gene (G1 rs73885319) was analyzed using the following primers (Midland, Texas).
Properties

\begin{tabular}{lll}
\hline & Forward & Reverse \\
\hline Sequence & $5^{\prime}$-CCAATCTTCAGTCAGTACCGC-3' & 5'-GGTCCGCCTGCAGAATC-3' $^{\prime}{ }^{\prime}$ \\
Length (bases) & 21 & 17 \\
GC content $(\%)$ & 52.4 & 64.7 \\
Melting temperature $\left({ }^{\circ} \mathrm{C}\right)$ & 55.5 & 56.3 \\
Molecular weight $(\mathrm{g} / \mathrm{mole})$ & 6326.2 & 5171.4
\end{tabular}

PCR amplification for APOL1 gene (G1 rs73885319) was performed separately in using applied Bio system 2720 thermal cycler (Singapore).

For APOL1 gene (G1 rs73885319): The cycling conditions for PCR were initial denaturation at $94^{\circ} \mathrm{C}$ for 1 minute 1 cycle, followed by 35 cycles of $94^{\circ} \mathrm{C}$ for 1 minute (melting), $58^{\circ} \mathrm{C}$ for 30 seconds (annealing), $72^{\circ} \mathrm{C}$ for 1 minute (extension) and final extension at $72^{\circ} \mathrm{C}$ for 8 minutes.

The amplification products separated by electrophoresis through $3 \%$ agarose gel stained with ethidium bromide.

The PCR products then was digested with HindIII (New England Biolabs) at $37^{\circ} \mathrm{C}$ for one hour (2.5 10 NE buffer 4, 1 HindIII, 6.5 dditilled water and 10 LPCR product). The Hind III digestive products were run by $4 \%$ agarose gel electrophoresis for 30 minutes and stained with ethidium bromide, and the bands were visualized under ultraviolet light.

For APOL1 gene (G1 rs73885319) A/G polymorphism, the uncut fragment was $176 \mathrm{bp}$ and digestion products were $132 \mathrm{bp}, 44 \mathrm{bp}$.

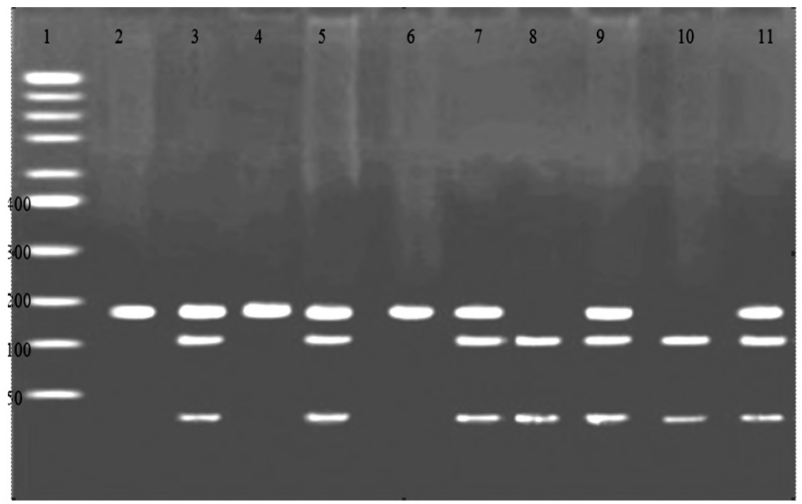

Fig. (1): For APOL1 gene (G1 rs73885319) A/G polymorphism, the uncut fragment was $176 \mathrm{bp}$ and digestion products were $132 \mathrm{bp}, 44 \mathrm{bp}$. ladder $50 \mathrm{bp}$ was used.

* Lanes 2,4 and 6 indicate AA genotype

* Lanes 3, 5, 7, 9 and 11 indicate $\mathrm{AG}$ genotypes.

* Lanes 8 and 10 indicate GG genotype.

E- Determination of APOL1 gene polymorphism (G1 APOL1 G1 rs60910145): PCR for APOL1 gene (G1 APOL1 G1 rs60910145) was carried out to a total volume of 25 cantaining 1 Lof forward and 1 -rezerse primers; 12.5ul of master mix (genecraft; Germany); (Stratagene; USA) and 0.5ul distal water (APOL1 G1 rs 60910145) was analyzed using the following primers (Midland, Texas). 
Properties Primers (rs60910145) (APOL1)

\begin{tabular}{lll}
\hline & Forward & Reverse \\
\hline Sequence & $5^{\prime}$-GGAAAT GAGCAGAGGAGTCAA-3' & $5^{\prime}$-TGTGCTCAGCTATGGAAATGC-3' \\
Length (bases) & 22 & 21 \\
GC content $(\%)$ & 20 & 47.6 \\
Melting temperature $\left({ }^{\circ} \mathrm{C}\right)$ & 55.4 & 55.7 \\
Molecular weight $(\mathrm{g} / \mathrm{mole})$ & 6906.5 & 6461.2 \\
\hline
\end{tabular}

PCR amplification for APOL1 gene (APOL1 G1 rs60910145) was performed separately in using applied Bio system 2720 thermal cycler (Singapore).

For APOL1 gene (G1 rs60910145): The cycling conditions for PCR were initial denaturation at $94^{\circ} \mathrm{C}$ for 1 minute 1 cycle, followed by 35 cycles of $94^{\circ} \mathrm{C}$ for 1 minute (melting), $58^{\circ} \mathrm{C}$ for 30 seconds (annealing), $72^{\circ} \mathrm{C}$ for 1 minute (extension) and final extension at $72^{\circ} \mathrm{C}$ for 8 minutes.

The amplification products separated by electrophoresis through 3\% agarose gel stained with ethidium bromide.

The PCR products then was digested with NspI (New England Biolabs) at $37^{\circ} \mathrm{C}$ for one hour $(2.5 \propto 1$ 10x NE buffer $4,1 \propto 1$ NspI, $6.5 \propto 1$ distilled water and $10 \propto 1$ PCR product). The NspI digestive products were run by $4 \%$ agarose gel electrophoresis for 30 minutes and stained with ethidium bromide, and the bands were visualized under ultraviolet light.

For APOL1 gene (G1 rs60910145) T/G polymorphism, the uncut fragment was 230bp and digestion products were $180 \mathrm{bp}, 50 \mathrm{bp}$.

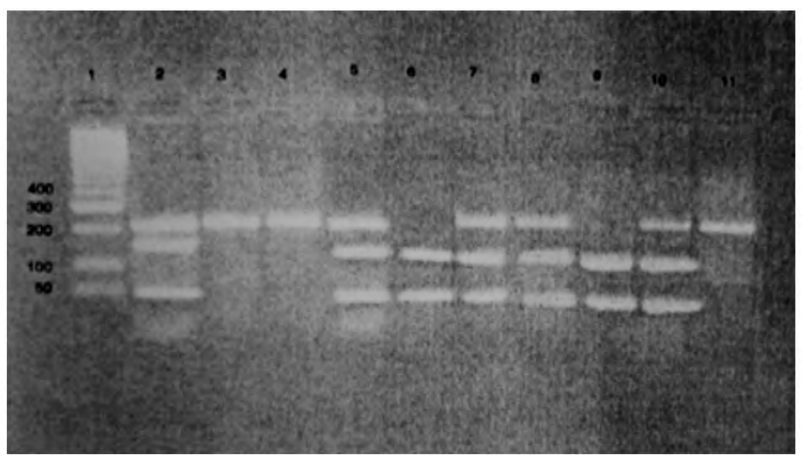

Fig. (2): For APOL1 gene (G1 rs60910145) T/G polymorphism, the uncut fragment was $230 \mathrm{bp}$ and digestion products were $180 \mathrm{bp}, 50 \mathrm{bp}$. ladder $50 \mathrm{bp}$ was used.

* Lanes 3, 4 and 11 indicate TT genotype.

* Lanes 2, 5, 7, 8 and 10 indicate TG genotypes.

* Lanes 6 and 9 indicate GG genotype.

F- Determination of APOL1 gene polymorphism (G2 rs 71785313): PCR for APOL1 gene (G2 rs 71785313 ) was carried out to a total volume of $25 \propto 1$, containing $1 \propto 1$ of forward and $1 \propto 1$ reverse primers; $12.5 \mathrm{ul}$ of master mix (genecraft; Germany); (Stratagene; USA) and 0.5ul distal water (Kalkan et al., 2013).

APOL1 gene (G1 rs71785313) was analyzed using the following primers (Midland, Texas).

\begin{tabular}{lll} 
Properties & \multicolumn{2}{c}{ Primers (rs71785313) (APOL1) } \\
\hline & Forward & Reverse \\
\hline Sequence & $5^{\prime}$-HEX-CTTCAGTCAGTACCATGC-3' & $5^{\prime}$-AGTTTGCATTTTGTCCTGGC-3 \\
Length (bases) & 20 & 20 \\
GC content $(\%)$ & 55 & 45 \\
Melting temperature $\left({ }^{\circ} \mathrm{C}\right)$ & 56 & 54.3 \\
Molecular weight $(\mathrm{g} / \mathrm{mole})$ & 6053 & 6105 \\
\hline
\end{tabular}

PCR amplification for APOL 1 gene (G2 rs 71785313) was performed separately in using applied Bio system 2720 thermal cycler (Singapore).

For APOL1 gene (G2 rs71785313): The cycling conditions for PCR were initial denaturation at $94^{\circ} \mathrm{C}$ for 1 minute 1 cycle, followed by 35 cycles of $94^{\circ} \mathrm{C}$ for 1 minute (melting), $58^{\circ} \mathrm{C}$ for 30 seconds (annealing), $72^{\circ} \mathrm{C}$ for 1 minute (extension) and final extension at $72^{\circ} \mathrm{C}$ for 8 minutes.

The amplification products separated by electrophoresis through 3\% agarose gel stained with ethidium bromide.

The PCR products then was digested with Mlu$\mathrm{CI}$ (New England Biolabs) at $37^{\circ} \mathrm{C}$ for one hour 
(2.5 10 NE buffer 4, 1 MMCI, 6.5 ditilled water and 10 PCR product). The MluCI digestive products were run by $4 \%$ agarose gel electrophoresis for 30 minutes and stained with ethidium bromide, and the bands were visualized under ultraviolet light.

For APOL1 gene (G1 rs71785313) I/D polymorphism, three genotypes were identified after electrophoresis, 197bp for insertion alleles (I/I), 197 and 57bp for insertion and deletion allele (I/D) and $57 \mathrm{bp}$ for the deletion allele (D/D).

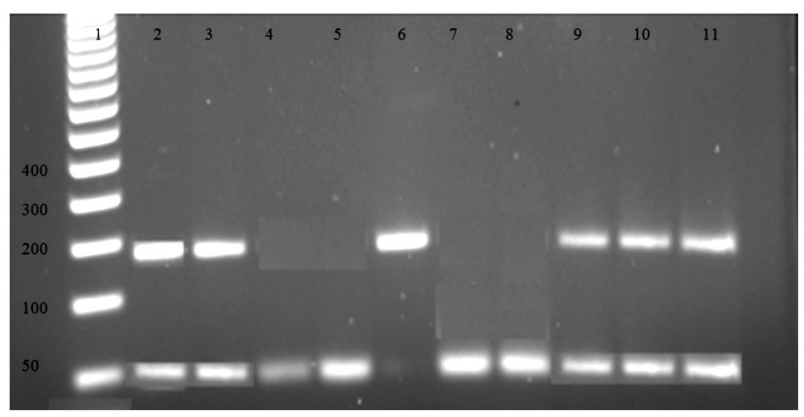

Fig. (3): For APOL1 gene (G2 rs71785313) I/D polymorphism, three genotypes were identified after electrophoresis, $197 \mathrm{bp}$ for insertion alleles (I/I), 197 and 57bp for insertion and deletion allele (I/D) and 57bp for the deletion allele (D/D). Ladder 50bp was used.

* Lane 6 indicates I/I genotypes.

* Lanes 2, 3, 9, 10 and 11 indicate I/D genotypes.

* Lanes 4, 5, 7 and 8 indicate D/D genotypes.

\section{Statistical analysis:}

The data collected were tabulated $\&$ analyzed by SPSS (statistical package for the social science software) statistical package Version 23.

Quantitative data were expressed as mean standard deviation $(\mathrm{X} \pm \mathrm{SD})$ and analyzed by applying $t$-test for comparison between two groups of normally distributed variables.

Qualitative data were expressed as number and percentage (No \& \%) and analyzed by applying $\chi^{2}$ (Chi 2) for comparison between two or more independent qualitative variables normally distributed. Allelic frequency of the polymorphism was calculated both in case and control samples.

The $\chi^{2}$ test was used to compare allele frequency of the APOL 1 gene polymorphism between studied groups. 95\% Confidence Interval (CI) was calculated to compare CKD risk around genotypes and alleles.

\section{Accuracy:}

- $p$-value $>0.05$ was considered statistically insignificant.

- $p$-value $<0.05$ was considered statistically significant.

- $p$-value $<0.001$ was considered statistically highly significant.

\section{Results}

Table (1): Demographic data of the studied groups.

\begin{tabular}{|c|c|c|c|c|}
\hline & $\begin{array}{l}\text { Group I } \\
\mathrm{N}=53\end{array}$ & $\begin{array}{l}\text { Group II } \\
\mathrm{N}=35\end{array}$ & $\begin{array}{c}\text { Test of } \\
\text { significance }\end{array}$ & $\begin{array}{c}p- \\
\text { value }\end{array}$ \\
\hline Age (years) & $\begin{array}{l}\text { Mean } \pm \text { SD } \\
60.4 \pm 10.6\end{array}$ & $\begin{array}{l}\text { Mean } \pm \text { SD } \\
58.8 \pm 8.4\end{array}$ & $\begin{array}{l}t \text {-test } \\
0.7\end{array}$ & 0.4 \\
\hline $\begin{array}{l}\text { Gender: } \\
\text { Male } \\
\text { Female }\end{array}$ & $\begin{array}{lc}\mathrm{N} & \% \\
28 & (52.8 \%) \\
25 & (47.2 \%)\end{array}$ & $\begin{array}{l}\mathrm{N} \% \\
19(54.2 \%) \\
16(45.8 \%)\end{array}$ & $\begin{array}{l}\text { Chi square } \\
0.8\end{array}$ & 0.9 \\
\hline $\begin{array}{l}\text { Smoking: } \\
\text { Non } \\
\text { Smoker }\end{array}$ & $\begin{array}{lc}\mathrm{N} & \% \\
33 & (62.3 \%) \\
20 & (37.7 \%)\end{array}$ & $\begin{array}{l}\mathrm{N} \% \\
20(57.1 \%) \\
15(42.9 \%)\end{array}$ & $\begin{array}{l}\text { Chi square } \\
0.6\end{array}$ & 0.6 \\
\hline $\begin{array}{l}\text { Duration of HTN } \\
\text { (years) }\end{array}$ & $\begin{array}{l}\text { Mean } \pm \text { SD } \\
11.3 \pm 1.5\end{array}$ & $\begin{array}{l}\text { Mean } \pm \text { SD } \\
11.5 \pm 1.5\end{array}$ & $\begin{array}{l}t \text {-test } \\
0.8\end{array}$ & 0.6 \\
\hline $\begin{array}{l}\text { Severity of HTN: } \\
\text { Mild } \\
\text { Moderate } \\
\text { Severe }\end{array}$ & $\begin{array}{lc}\mathrm{N} & \% \\
11 & (20.7 \%) \\
23 & (43.3 \%) \\
19 & (36 \%)\end{array}$ & $\begin{array}{l}\mathrm{N} \% \\
13(37.1 \%) \\
15(42.8 \%) \\
7(20.1 \%)\end{array}$ & $\begin{array}{l}\text { Chi square } \\
0.9\end{array}$ & 0.1 \\
\hline $\begin{array}{l}\text { Social class: } \\
\text { High } \\
\text { Moderate } \\
\text { Low }\end{array}$ & $\begin{array}{lc}\mathrm{N} & \% \\
19 & (35.8 \%) \\
18 & (33.9 \%) \\
16 & (30.1 \%)\end{array}$ & $\begin{array}{l}\mathrm{N} \% \\
13(10.4 \%) \\
14(13.3 \%) \\
8(25.7 \%)\end{array}$ & $\begin{array}{l}\text { Chi square } \\
0.5\end{array}$ & 0.7 \\
\hline BMI $\left(\mathrm{Kg} / \mathrm{m}^{2}\right)$ & $\begin{array}{l}\text { Mean } \pm \text { SD } \\
30.6 \pm 4.03\end{array}$ & $\begin{array}{l}\text { Mean } \pm \text { SD } \\
30.9 \pm 4.3\end{array}$ & $\begin{array}{l}t \text {-test } \\
0.3\end{array}$ & 0.7 \\
\hline
\end{tabular}


This table shows the demographic data of the studied groups of patients.

In this table: There is no significant statistical difference between both groups as regard: Age, gender, smoking, BMI, HTN duration; HTN severity or the socio-economic class.

This table shows the laboratory data of the studied groups of patients.

Table (2): Laboratory data of the studied groups.

\begin{tabular}{|c|c|c|c|c|}
\hline & $\begin{array}{c}\text { Group I } \\
\mathrm{N}=53\end{array}$ & $\begin{array}{c}\text { Group II } \\
\mathrm{N}=35\end{array}$ & $\begin{array}{c}\text { Test of } \\
\text { significance } \\
\text { Independent } t \text {-test }\end{array}$ & $\begin{array}{c}p- \\
\text { value }\end{array}$ \\
\hline $\mathrm{Hb}(\mathrm{gm} / \mathrm{dl})$ & $\begin{array}{l}\text { Mean } \pm \text { SD } \\
12.1 \pm 1.7\end{array}$ & $\begin{array}{l}\text { Mean } \pm \text { SD } \\
10.2 \pm 1.3\end{array}$ & 5.2 & 0.0001 \\
\hline WBCs $\left(* 10^{\wedge} 3 / \mathrm{C} . \mathrm{mm}\right)$ & $6.3 \pm 2.1$ & $6.4 \pm 2.2$ & 0.3 & 0.7 \\
\hline PLTs $\left(* 10^{\wedge} 3 / \mathrm{C} . \mathrm{mm}\right)$ & $244.9 \pm 62.2$ & $223.7 \pm 54.2$ & 1.6 & 0.1 \\
\hline FBS $(\mathrm{mg} / \mathrm{dl})$ & $85.5 \pm 8.5$ & $83.6 \pm 8.5$ & 1.04 & 0.2 \\
\hline Cholesterol (mg/dl) & $225.7 \pm 40.2$ & $252.2 \pm 46.3$ & 2.8 & 0.006 \\
\hline Triglycerides (mg/dl) & $184.7 \pm 39.4$ & $199.2 \pm 27.2$ & 1.9 & 0.06 \\
\hline HDL (mg/dl) & $41.5 \pm 4.3$ & $40.03 \pm 3.6$ & 1.6 & 0.09 \\
\hline LDL (mg/dl) & $147.2 \pm 37.07$ & $172.3 \pm 44.7$ & 2.8 & 0.005 \\
\hline BUN (mg/dl) & $20.6 \pm 1.4$ & $79.1 \pm 19.4$ & 21.9 & 0.0001 \\
\hline Creatinine (mg/dl) & $1.08 \pm 0.12$ & $3.8 \pm 0.7$ & 25.7 & 0.0001 \\
\hline $\mathrm{Na}(\mathrm{mmol} / \mathrm{l})$ & $138.6 \pm 3.7$ & $140.03 \pm 3.3$ & 1.7 & 0.07 \\
\hline $\mathrm{K}(\mathrm{mmol} / \mathrm{l})$ & $4.04 \pm 0.4$ & $4.2 \pm 0.54$ & 0.2 & 0.03 \\
\hline eGFR (ml/min) & $93.8 \pm 14.7$ & $38.6 \pm 9.2$ & 19.7 & 0.0001 \\
\hline Alb/creat (mg/gm) & $200 \pm 100$ & $1100 \pm 500$ & 13.4 & 0.0001 \\
\hline 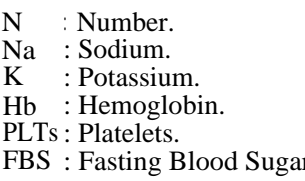 & \multicolumn{4}{|c|}{$\begin{array}{l}\text { e-GFR: Estimated Glomerular Filtratio } \\
\text { SD : Standard Deviation. } \\
\text { HDL : High Density Lipoproteins. } \\
\text { LDL : Low Density Lipoproteins. } \\
\text { BUN : Blood Urea Nitrogen. } \\
\text { WBCs : White Blood Cells. }\end{array}$} \\
\hline
\end{tabular}

In this table, there was a significant statistical difference between both groups as regard: $\mathrm{Hb}$, cholesterol, LDL, BUN, creatinine, K, eGFR and

albumin/creatinine ratio (anemia, dyslipidemia, hyperkalemia and impaired kidney function are more frequent in Group II).

Table (3): APOL1distribution in the studied groups.

\begin{tabular}{|c|c|c|c|c|}
\hline & $\begin{array}{c}\text { Group I } \\
\mathrm{N}=53\end{array}$ & $\begin{array}{c}\text { Group II } \\
\mathrm{N}=35\end{array}$ & $\begin{array}{c}\text { Test of } \\
\text { significance } \\
\chi^{2}\end{array}$ & $\begin{array}{c}p- \\
\text { value }\end{array}$ \\
\hline $\begin{array}{l}\text { APOL1 G1 rs73885319: } \\
\text { AA } \\
\text { AG } \\
\text { GG }\end{array}$ & $\begin{array}{ll}\mathrm{N} & \% \\
18 & (33.9 \%) \\
33 & (62.2 \%) \\
2 & (3.9 \%)\end{array}$ & $\begin{array}{lc}\mathrm{N} & \% \\
1 & (2.8 \%) \\
24 & (68.5 \%) \\
10 & (28.7 \%)\end{array}$ & 19.8 & 0.0001 \\
\hline $\begin{array}{c}\text { Allele: } \\
\text { A } \\
\text { G }\end{array}$ & $\begin{array}{l}69(65.1 \%) \\
37(34.9 \%)\end{array}$ & $\begin{array}{l}26(37.1 \%) \\
44(62.9 \%)\end{array}$ & 1.6 to 5.9 & 0.0003 \\
\hline $\begin{array}{l}\text { APOL1 G1 rs60910145: } \\
\text { TT } \\
\text { TG } \\
\text { GG }\end{array}$ & $\begin{array}{l}\mathrm{N} \quad \% \\
15(28.3 \%) \\
36(67.9 \%) \\
2 \quad(3.8 \%)\end{array}$ & $\begin{array}{lc}\mathrm{N} & \% \\
1 & (2.8 \%) \\
22 & (62.8 \%) \\
12 & (34.4 \%)\end{array}$ & 19.9 & 0.0001 \\
\hline $\begin{array}{c}\text { Allele: } \\
\text { T } \\
\text { G }\end{array}$ & $\begin{array}{l}66(62.2 \%) \\
40(37.8 \%)\end{array}$ & $\begin{array}{l}24(34.2 \%) \\
46(65.8 \%)\end{array}$ & 1.6 to 5.9 & 0.0003 \\
\hline $\begin{array}{l}\text { APOL1 G2 rs71785313: } \\
\quad \text { II } \\
\text { DI } \\
\text { DD }\end{array}$ & $\begin{array}{l}\mathrm{N} \quad \% \\
13(24.6 \%) \\
38(71.6 \%) \\
2(3.8 \%)\end{array}$ & $\begin{array}{lc}\mathrm{N} & \% \\
1 & (2.8 \%) \\
23 & (65.7 \%) \\
11 & (31.5 \%)\end{array}$ & 13.2 & 0.0001 \\
\hline $\begin{array}{c}\text { Allele: } \\
\text { I } \\
\text { D }\end{array}$ & $\begin{array}{l}64(60.3 \%) \\
42(39.7 \%)\end{array}$ & $\begin{array}{l}25(35.7 \%) \\
45(64.3 \%)\end{array}$ & 1.4 to 5.1 & 0.001 \\
\hline
\end{tabular}

N: Number. 
This table shows the APOL1 genotypes \& alleles distribution in the studied groups.

In this table, there is significant statistical difference between both groups as regard APOL 1
G1 rs73885319, G1 rs60910145 and G2 rs 71785313 genotypes and alleles (the abnormal genotypes AG, GG, TG, DI, DD are more frequent in Group II).

Table (4): Distribution of APOL1 G1 rs73885319 according to demographic data of the studied groups $(n=88)$.

\begin{tabular}{|c|c|c|c|c|c|}
\hline & \multicolumn{5}{|c|}{ APOL1 G1 rs73885319 } \\
\hline & AA & $\mathrm{AG}$ & GG & $\begin{array}{c}\text { Test of } \\
\text { significance }\end{array}$ & $\begin{array}{c}p- \\
\text { value }\end{array}$ \\
\hline Gender: & $\mathrm{N} \quad \%$ & $\mathrm{~N} \quad \%$ & $\mathrm{~N} \%$ & $\mathrm{Chi}^{2}$ & \\
\hline Male & $12(63.3 \%)$ & $28(49.1 \%)$ & $6(50 \%)$ & 0.9 & 0.6 \\
\hline Female & $7 \quad(36.7 \%)$ & $29(50.9 \%)$ & $6(50 \%)$ & & \\
\hline \multicolumn{6}{|l|}{ Social class: } \\
\hline High & $8(42.2 \%)$ & $20(35.1 \%)$ & $4(33.3 \%)$ & 0.7 & 0.9 \\
\hline Moderate & $7(36.7 \%)$ & $20(35.1 \%)$ & $5(41.7 \%)$ & & \\
\hline Low & $4(21.1 \%)$ & $17(29.8 \%)$ & $3(25 \%)$ & & \\
\hline \multicolumn{6}{|l|}{ Smoking: } \\
\hline No & $11(57.8 \%)$ & $36(63.1 \%)$ & $6(50 \%)$ & 0.7 & 0.6 \\
\hline Yes & $8 \quad(42.2 \%)$ & $21(36.9 \%)$ & $6(50 \%)$ & & \\
\hline \multicolumn{6}{|c|}{ HTN severity: } \\
\hline Mild & $3(15.7 \%)$ & $18(31.5 \%)$ & $3(25 \%)$ & 2.6 & 0.6 \\
\hline Moderate & $11(57.8 \%)$ & $22(38.7 \%)$ & $5(41.7 \%)$ & & \\
\hline Sever & $5 \quad(26.5 \%)$ & $17(29.8 \%)$ & $4(33.3 \%)$ & & \\
\hline
\end{tabular}

This table shows the association between APOL1 G1 rs73885319 and the demographic data of the studied groups (both groups $n=88$ ): There was no significant statistical difference between AA, AG or GG genotypes as regard patient gender, social class, smoking, and hypertension severity.

Table (5): Distribution of APOL1 G1 rs73885319 according to laboratory parameters of the studied groups (both groups $\mathrm{n}=88$ ).

\begin{tabular}{|c|c|c|c|c|c|c|c|c|}
\hline & \multicolumn{8}{|c|}{ APOL1 G1 rs73885319 } \\
\hline & AA & AG & GG & $\begin{array}{c}\text { Test of } \\
\text { significance }\end{array}$ & $\begin{array}{c}p- \\
\text { value }\end{array}$ & $p_{1}$ & $p_{2}$ & $p_{3}$ \\
\hline $\mathrm{Hb}(\mathrm{gm} / \mathrm{dl})$ & $\begin{array}{l}\text { Mean } \pm \text { SD } \\
12.3 \pm 1.8\end{array}$ & $\begin{array}{l}\text { Mean } \pm \text { SD } \\
11.2 \pm 1.7\end{array}$ & $\begin{array}{l}\text { Mean } \pm \text { SD } \\
10.5 \pm 1.7\end{array}$ & $\begin{array}{l}\text { One way } \\
\text { ANOVE } 4.2\end{array}$ & 0.01 & 0.06 & 0.01 & 0.3 \\
\hline CHOL (mg/dl) & $202.4 \pm 30.7$ & $247.5 \pm 41.6$ & $236.2 \pm 53.9$ & 8.6 & 0.0001 & 0.0001 & 0.7 & 0.6 \\
\hline TG (mg/dl) & $159.1 \pm 32.2$ & $202.6 \pm 31.5$ & $182.5 \pm 26.7$ & 14.4 & 0.0001 & 0.0001 & 0.08 & 0.6 \\
\hline HDL (mg/dl) & $44.6 \pm 4.6$ & $39.2 \pm 3.07$ & $42.9 \pm 3.9$ & 19.2 & 0.0001 & 0.0001 & 0.3 & 0.004 \\
\hline LDL (mg/dl) & $125.9 \pm 28.7$ & $167.7 \pm 38.3$ & $156.8 \pm 52.7$ & 8.2 & 0.01 & 0.0001 & 0.08 & 0.6 \\
\hline Creat (mg/dl) & $1.2 \pm 0.6$ & $2.1 \pm 1.4$ & $3.5 \pm 1.3$ & 11.3 & 0.0001 & 0.02 & 0.0001 & 0.004 \\
\hline eGFR (ml/min) & $88.2 \pm 18.4$ & $71.8 \pm 30.6$ & $45.9 \pm 24.3$ & 8.5 & 0.0001 & 0.07 & 0.0001 & 0.01 \\
\hline Alb/creat (mg/gm) & $300 \pm 200$ & $600 \pm 500$ & $1100 \pm 500$ & 9.8 & 0.0001 & 0.08 & 0.0001 & 0.004 \\
\hline $\begin{array}{ll}\mathrm{SD} & : \text { Standard Dev } \\
\mathrm{Hb} & : \text { Hemoglobin. } \\
\mathrm{CHOL} & : \text { Cholesterol. } \\
\mathrm{TG} & \text { : Triglycerides. } \\
\mathrm{HDL} & \text { : High Density } \\
\mathrm{LDL} & \text { : Low Density }\end{array}$ & $\begin{array}{l}\text { ation. } \\
\text { Lipoproteins. } \\
\text { ipoproteins. }\end{array}$ & & $\begin{array}{l}\text { Creat } \\
\text { e-GFR } \\
\text { Alb/creat } \\
p_{1} \\
p_{2} \\
p_{3}\end{array}$ & $\begin{aligned} \text { : Creatinine. } \\
: \text { Estimated Gl } \\
\mathrm{t}: \text { Albumin/crea } \\
: \text { Between AA } \\
: \text { Between AA } \\
: \text { Between AG }\end{aligned}$ & $\begin{array}{l}\text { merular } \\
\text { inine rati } \\
\text { and AG ge } \\
\text { and GG g } \\
\text { and GG g }\end{array}$ & $\begin{array}{l}\text { iltration } \\
\text { notypes. } \\
\text { notypes. } \\
\text { notypes. }\end{array}$ & ate. & \\
\hline
\end{tabular}

This table shows the association between APOL1 G1 rs73885319 and the laboratory parameters of the studied groups (both groups $n=88$ ).
There was significant statistical difference between the three genotypes as regard the laboratry data as: Haemoglobin, cholesterol, triglycerides, 
HDL, LDL, creatinine, eGFR, and albumin/creatinine ratio.

This significant statistical difference was evident between AA and AG genotypes $\left(p_{1}\right)$ as regard to cholesterol, triglycerides, HDL, LDL, creatinine and between AA and GG genotypes $\left(p_{2}\right)$ as regard creatinine, eGFR and albumin/ creatinine ratio.

While between AG and GG genotypes ( $p 3$ ), there was significant statistical difference as regard HDL, creatinine, eGFR and albumin/creatinine ratio.

Table (6): Distribution of APOL1 G1 rs60910145 according to demographic data of the studied groups (both groups $n=88$ ).

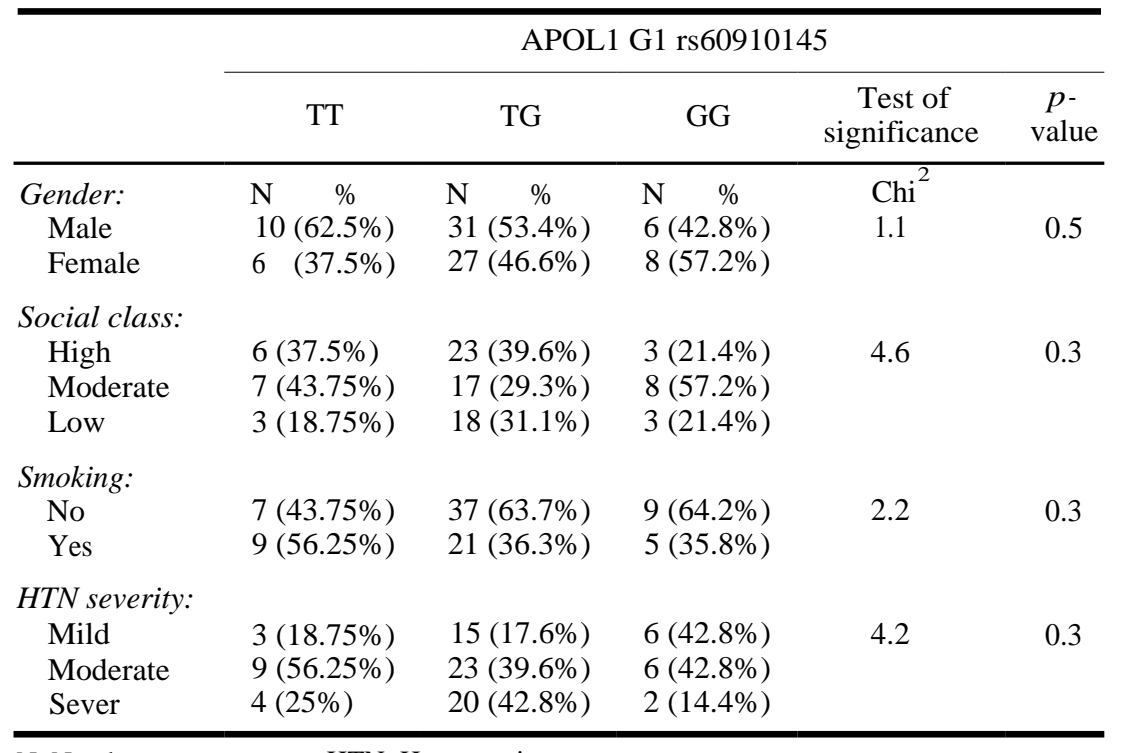

$\mathrm{N}$ : Number.

HTN: Hypertension.

This table shows the association between APOL1 G1 rs60910195 and the demographic data of the studied groups (both groups $n=88$ ): There was no significant statistical difference between TT, TG or GG genotypes as regard patient gender, social class, smoking, and hypertension severity.

Table (7): Distribution of APOL1 G1 rs60910145 according to laboratory parameters of the studied groups (both groups $\mathrm{n}=88$ ).

\begin{tabular}{|c|c|c|c|c|c|c|c|c|}
\hline & \multicolumn{8}{|c|}{ APOL1 G1 rs60910145 } \\
\hline & TT & TG & GG & $\begin{array}{c}\text { Test of } \\
\text { significance }\end{array}$ & $\begin{array}{c}p- \\
\text { value }\end{array}$ & $p_{1}$ & $p_{2}$ & $p_{3}$ \\
\hline $\mathrm{Hb}(\mathrm{gm} / \mathrm{dl})$ & $\begin{array}{l}\text { Mean } \pm \text { SD } \\
12.6 \pm 2.01\end{array}$ & $\begin{array}{l}\text { Mean } \pm \text { SD } \\
11.2 \pm 1.6\end{array}$ & $\begin{array}{l}\text { Mean } \pm \text { SD } \\
10.3 \pm 1.7\end{array}$ & $\begin{array}{l}\text { One way } \\
\text { ANOVE } 7\end{array}$ & 0.001 & 0.01 & 0.001 & 0.1 \\
\hline CHOL (mg/dl) & $193 \pm 37.05$ & $247.3 \pm 41.3$ & $240 \pm 36.4$ & 11.7 & 0.0001 & 0.0001 & 0.005 & 0.8 \\
\hline TG (mg/dl) & $153.1 \pm 35.5$ & $200.1 \pm 29.9$ & $193.1 \pm 30.7$ & 14.3 & 0.0001 & 0.0001 & 0.002 & 0.7 \\
\hline HDL (mg/dl) & $45.4 \pm 4.7$ & $39.4 \pm 2.7$ & $41.7 \pm 4.4$ & 18.9 & 0.0001 & 0.0001 & 0.01 & 0.7 \\
\hline LDL (mg/dl) & $116.8 \pm 34.4$ & $167.8 \pm 35.1$ & $159.5 \pm 34.9$ & 11.5 & 0.0001 & 0.0001 & 0.007 & 0.7 \\
\hline Creat (mg/dl) & $1.3 \pm 0.7$ & $2.09 \pm 1.4$ & $3.4 \pm 1.2$ & 10.4 & 0.0001 & 0.08 & 0.0001 & 0.002 \\
\hline eGFR (ml/min) & $88.2 \pm 21.3$ & $73.01 \pm 29.8$ & $48.5 \pm 26.3$ & 7.9 & 0.002 & 0.1 & 0.001 & 0.01 \\
\hline Alb/creat (mg/gm) & $0.2 \pm 0.2$ & $0.6 \pm 0.5$ & $1.01 \pm 0.5$ & 6.9 & 0.001 & 0.09 & 0.001 & 0.03 \\
\hline $\begin{array}{ll}\mathrm{SD} & : \text { Standard Dev } \\
\mathrm{Hb} & \text { : Hemoglobin. } \\
\mathrm{CHOL} & \text { : Cholesterol. } \\
\mathrm{TG} & \text { : Triglycerides } \\
\mathrm{HDL} & \text { : High Density } \\
\mathrm{LDL} & \text { : Low Density }\end{array}$ & $\begin{array}{l}\text { ation. } \\
\text { Lipoproteins. } \\
\text { ipoproteins. }\end{array}$ & & $\begin{array}{ll}\text { Creat } & : \\
\text { e-GFR } & : 1 \\
\text { Alb/creat } & : \\
p_{1} & : 1 \\
p_{2} & : 1 \\
p_{3} & : 1\end{array}$ & $\begin{array}{l}\text { reatinine. } \\
\text { stimated Glome } \\
\text { lbumin/creatinin } \\
\text { etween TT and T } \\
\text { etween TT and c } \\
\text { etween TG and }\end{array}$ & $\begin{array}{l}\text { ular Filtr } \\
\text { e ratio. } \\
\text { G genoty } \\
\text { JG genoty } \\
\text { JG genoty }\end{array}$ & $\begin{array}{l}\text { ion Rate. } \\
\text { es. } \\
\text { pes. } \\
\text { pes. }\end{array}$ & & \\
\hline
\end{tabular}

This table shows the association between APOL1 G1 rs60910195 and the laboratory data of the studied groups (both groups $n=88$ ): There was significant statistical difference between the three 
genotypes as regard the laboratry data as: Haemoglobin, cholesterol, triglycerides, HDL, LDL, creatinine, eGFR, and albumin/ creatinine ratio.

This significant statistical difference was evident between TT and TG genotypes $\left(p_{1}\right)$ as regard cholesterol, triglycerides, HDL, LDL, haemoglobin and between TT and GG genotypes $\left(p_{2}\right)$ as regard haemoglobin, cholesterol, triglycerides, HDL, LDL, creatinine, eGFR, and albumin/creatinine ratio.

While between TG and GG genotypes $\left(p_{3}\right)$, there was significant statistical difference as regard creatinine, eGFR and albumin/creatinine ratio.

Table (8): Distribution of APOL1 G2 rs71785313 according to demographic data of the studied groups (both groups $n=88$ ).

\begin{tabular}{|c|c|c|c|c|c|}
\hline & \multicolumn{5}{|c|}{ APOL1 G2 rs71785313 } \\
\hline & II & ID & DD & $\begin{array}{c}\text { Test of } \\
\text { significance }\end{array}$ & $\begin{array}{c}p- \\
\text { value }\end{array}$ \\
\hline Gender: & $\mathrm{N} \quad \%$ & $\mathrm{~N}$ & $\mathrm{~N} \quad \%$ & $\mathrm{Chi}^{2}$ & \\
\hline Male & $5(38.4 \%)$ & $31(50.8 \%)$ & $5(35.7 \%)$ & 1.4 & 0.4 \\
\hline Female & $8(61.6 \%)$ & $30(49.2 \%)$ & $9(64.3 \%)$ & & \\
\hline \multicolumn{6}{|l|}{ Social class: } \\
\hline High & $1(7.6 \%)$ & $23(37.7 \%)$ & $8(57.6 \%)$ & 1.5 & 0.3 \\
\hline Moderate & $9(69.2 \%)$ & $21(34.4 \%)$ & $2(14.4 \%)$ & & \\
\hline Low & $3(23.2 \%)$ & $17(27.9 \%)$ & $4(28.8 \%)$ & & \\
\hline \multicolumn{6}{|l|}{ Smoking: } \\
\hline No & $10(76.8 \%)$ & $36(59.1 \%)$ & $7(50 \%)$ & 3.07 & 0.2 \\
\hline Yes & $3 \quad(23.2 \%)$ & $25(40.9 \%)$ & $7(50 \%)$ & & \\
\hline \multicolumn{6}{|l|}{ HTN severity: } \\
\hline Mild & $4(30.4 \%)$ & $17(27.9 \%)$ & $3(21.2 \%)$ & 1.5 & 0.8 \\
\hline Moderate & $6(46.4 \%)$ & $24(39.3 \%)$ & $7(50 \%)$ & & \\
\hline Sever & $3(23.2 \%)$ & $20(32.8 \%)$ & $4(28.8 \%)$ & & \\
\hline
\end{tabular}

This table shows the association between APOL1 G2 rs71785313 and the demographic data of the studied groups (both groups $n=88$ ): There was no significant statistical difference between II, ID or DD genotypes as regard patient gender, social class, smoking, and hypertension severity.

Table (9): Distribution of APOL1 G2 rs71785313 according to laboratory parameters of the studied groups (both groups $\mathrm{n}=88$ ).

\begin{tabular}{|c|c|c|c|c|c|c|c|c|}
\hline & \multicolumn{8}{|c|}{ APOL1 G2 rs71785313 } \\
\hline & II & ID & DD & $\begin{array}{c}\text { Test of } \\
\text { significance }\end{array}$ & $\begin{array}{c}p- \\
\text { value }\end{array}$ & $p_{1}$ & $p_{2}$ & $p_{3}$ \\
\hline $\mathrm{Hb}(\mathrm{gm} / \mathrm{dl})$ & $\begin{array}{l}\text { Mean } \pm \text { SD } \\
11.7 \pm 1.6\end{array}$ & $\begin{array}{l}\text { Mean } \pm \text { SD } \\
11.4 \pm 2\end{array}$ & $\begin{array}{l}\text { Mean } \pm \text { SD } \\
10.7 \pm 1.3\end{array}$ & 1.1 & 0.3 & 0.8 & 0.3 & 0.4 \\
\hline CHOL (mg/dl) & $188.8 \pm 36.5$ & $239.5 \pm 34.9$ & $273.2 \pm 49.6$ & 17.3 & 0.0001 & 0.0001 & 0.0001 & 0.01 \\
\hline TG (mg/dl) & $152 \pm 36.4$ & $194.1 \pm 27.6$ & $214.8 \pm 38.2$ & 15.3 & 0.0001 & 0.0001 & 0.0001 & 0.07 \\
\hline HDL (mg/dl) & $45.9 \pm 4.1$ & $40.2 \pm 2.8$ & $38.9 \pm 5.3$ & 17.4 & 0.0001 & 0.0001 & 0.0001 & 0.4 \\
\hline LDL (mg/dl) & $112.5 \pm 35.8$ & 160.232 .6 & $191.5 \pm 49.03$ & 17.1 & 0.0001 & 0.0001 & 0.0001 & 0.01 \\
\hline Creat (mg/dl) & $1.2 \pm 0.7$ & $2.1 \pm 1.4$ & $3.06 \pm 1.08$ & 5.8 & 0.004 & 0.07 & 0.003 & 0.08 \\
\hline eGFR (ml/min) & $90.1 \pm 18.2$ & $72.1 \pm 31.2$ & $51.4 \pm 21.2$ & 6.2 & 0.003 & 0.08 & 0.002 & 0.05 \\
\hline Alb/creat (mg/gm) & $300 \pm 400$ & $500 \pm 500$ & $1100 \pm 700$ & 7.3 & 0.001 & 0.3 & 0.001 & 0.004 \\
\hline $\begin{array}{ll}\mathrm{SD} & : \text { Standard Dev } \\
\mathrm{Hb} & : \text { Hemoglobin. } \\
\mathrm{CHOL} & : \text { Cholesterol. } \\
\mathrm{TG} & \text { : Triglycerides. } \\
\mathrm{HDL} & \text { : High Density } \\
\mathrm{LDL} & \text { : Low Density }\end{array}$ & $\begin{array}{l}\text { ation. } \\
\text { Lipoproteins. } \\
\text { Lipoproteins. }\end{array}$ & & $\begin{array}{ll}\text { Creat } & : \mathrm{C} \\
\text { e-GFR } & : \mathrm{E} \\
\text { Alb/creat } & : \mathrm{A} \\
p_{1} & : \mathrm{B} \\
p_{2} & : \mathrm{B} \\
p_{3} & : \mathrm{B}\end{array}$ & $\begin{array}{l}\text { eatinine. } \\
\text { timated Glomer } \\
\text { bumin/creatinin } \\
\text { tween II and ID } \\
\text { tween II and DI } \\
\text { tween ID and D }\end{array}$ & $\begin{array}{l}\text { ular Filtrat } \\
\text { ratio. } \\
\text { genotypes } \\
\text { genotype } \\
\text { D genotyp }\end{array}$ & ion Rate. & & \\
\hline
\end{tabular}

This table shows the association between APOL1 G2 rs71785313 and the laboratory data of the studied groups (both groups $n=88$ ): There was significant statistical difference between the three 
genotypes as regard the laboratry data as: Cholesterol, triglycerides, HDL, LDL, creatinine, eGFR, and albumin/creatinine ratio.

This significant statistical difference was evident between II and ID genotypes $\left(p_{1}\right)$ as regard cholesterol, triglycerides, HDL, LDL and between II and DD genotypes ( $p 2$ ) as regard to cholesterol, triglycerides, HDL, LDL, creatinine, eGFR, and albumin/creatinine ratio.

While between ID and DD genotypes ( $p 3)$, there was significant statistical difference as regard cholesterol, LDL and albumin/creatinine ratio.

Table (10): Baseline characteristics by allele combination as regard the demographic data (in both groups $n=88$ ).

\begin{tabular}{|c|c|c|c|c|c|}
\hline & $\begin{array}{l}\text { No risk } \\
\mathrm{N}=3\end{array}$ & $\begin{array}{l}1 \text { risk } \\
\mathrm{N}=14\end{array}$ & $\begin{array}{l}2 \text { risk } \\
N=71\end{array}$ & $\begin{array}{c}\text { Test of } \\
\text { significance }\end{array}$ & $\begin{array}{c}p- \\
\text { value }\end{array}$ \\
\hline Gender: & $\mathrm{N} \quad \%$ & $\mathrm{~N} \quad \%$ & $\mathrm{~N} \quad \%$ & Fisher exact & \\
\hline Male & $2(66.7 \%)$ & $9(64.3 \%)$ & $35(49.3 \%)$ & 1.06 & 0.5 \\
\hline Female & $1(33.3 \%)$ & $5(35.7 \%)$ & $36(50.7 \%)$ & & \\
\hline \multicolumn{6}{|l|}{ Social class: } \\
\hline High & $2(66.7 \%)$ & $5(46.6 \%)$ & $25(32.1 \%)$ & 0.1 & 0.9 \\
\hline Moderate & $1(33.3 \%)$ & $5(26.7 \%)$ & $26(39.2 \%)$ & & \\
\hline Low & $0(0 \%)$ & $4(26.7 \%)$ & $20(28.7 \%)$ & & \\
\hline \multicolumn{6}{|l|}{ Smoking: } \\
\hline No & $2(66.7 \%)$ & $8(60 \%)$ & $43(60.7 \%)$ & 1.6 & 0.8 \\
\hline Yes & $1(33.3 \%)$ & $6(40 \%)$ & $28(39.3 \%)$ & & \\
\hline \multicolumn{6}{|c|}{ HTN severity: } \\
\hline Mild & $0(0 \%)$ & $4(13.4 \%)$ & $20(32.1 \%)$ & 3.4 & 0.4 \\
\hline Moderate & $2(66.7 \%)$ & $8(46.6 \%)$ & $28(37.5 \%)$ & & \\
\hline Sever & $1(33.3 \%)$ & $2(40 \%)$ & $23(30.4 \%)$ & & \\
\hline $\mathrm{N}$ & & & & & \\
\hline HTN & sion. & & & & \\
\hline No risk : No & enotypes (A & TT + II). & & & \\
\hline One risk : $\mathrm{Ab}$ & single geno & e $(\mathrm{AG}, \mathrm{TG}, \mathrm{C}$ & DI or DD). & & \\
\hline
\end{tabular}

This table shows the baseline characteristics by allele combination as regard the patients demographic data: There was no significant statistical difference between absent risk alleles, the presence of one risk allele or two risk allels as regard to the patient demographic data.

Table (11): Baseline characteristics by allele combination as regard the laboratory parameters (both groups $\mathrm{n}=88)$.

\begin{tabular}{|c|c|c|c|c|c|c|c|c|}
\hline & $\begin{array}{c}\text { No risk } \\
\mathrm{N}=3\end{array}$ & $\begin{array}{l}1 \text { risk } \\
\mathrm{N}=14\end{array}$ & $\begin{array}{l}2 \text { risk } \\
\mathrm{N}=71\end{array}$ & $\begin{array}{c}\text { Test of } \\
\text { significance }\end{array}$ & $\begin{array}{c}p- \\
\text { value }\end{array}$ & $p_{1}$ & $p_{2}$ & $p_{3}$ \\
\hline \multirow[t]{2}{*}{$\mathrm{Hb}(\mathrm{gm} / \mathrm{dl})$} & Mean \pm SD & Mean \pm SD & Mean \pm SD & One way & 0.03 & 0.9 & 0.3 & 0.05 \\
\hline & $12.5 \pm 2.2$ & $12.3 \pm 1.9$ & $11.1 \pm 1.7$ & ANOVA 3.4 & & & & \\
\hline CHOL (mg/dl) & $158.3 \pm 12.6$ & $194.8 \pm 35.4$ & $247.7 \pm 38.5$ & 18.1 & 0.0001 & 0.2 & 0.0001 & 0.0001 \\
\hline TG (mg/dl) & $108.6 \pm 35.5$ & $157.6 \pm 30.1$ & $200.4 \pm 28.2$ & 26.4 & 0.0001 & 0.02 & 0.0001 & 0.0001 \\
\hline HDL (mg/dl) & $51.6 \pm 0.5$ & $45 \pm 3.6$ & $39.6 \pm 2.9$ & 36.9 & 0.0001 & 0.003 & 0.0001 & 0.0001 \\
\hline LDL (mg/dl) & $84.9 \pm 9.5$ & $118.3 \pm 32.7$ & $167.9 \pm 36.9$ & 17.7 & 0.0001 & 0.3 & 0.0001 & 0.0001 \\
\hline Creat (mg/dl) & $1.1 \pm 0.1$ & $1.3 \pm 0.7$ & $2.1 \pm 1.4$ & 4.3 & 0.01 & 0.9 & 0.2 & 0.02 \\
\hline eGFR (ml/min) & $95.6 \pm 4.9$ & $87.1 \pm 21.6$ & $67.6 \pm 30.7$ & 3.5 & 0.03 & 0.8 & 0.2 & 0.03 \\
\hline Alb/creat (mg/gm) & $300 \pm 50$ & $200 \pm 200$ & $600 \pm 600$ & 3.4 & 0.03 & 0.9 & 0.5 & 0.04 \\
\hline \\
\hline \multicolumn{9}{|c|}{ SD : Standard Deviation. } \\
\hline \multicolumn{3}{|c|}{$\mathrm{Hb} \quad$ : Hemoglobin. } & No risk : & \multicolumn{5}{|c|}{ : Normal genotypes (AA + TT + II) } \\
\hline \multicolumn{3}{|l|}{ CHOL : Cholesterol. } & One risk : & \multicolumn{5}{|c|}{ : Single abnormal genotype (AG, TG, GG, DI or DD). } \\
\hline \multicolumn{3}{|c|}{ TG : Triglycerides. } & Two risk : & \multicolumn{5}{|c|}{ : Two abnormal genotype (G1/G1), (G1/G2) or $(\mathrm{G} 2 / \mathrm{G} 2)$. } \\
\hline \multirow{2}{*}{\multicolumn{3}{|c|}{$\begin{array}{l}\text { HDL : High Density Lipoproteins. } \\
\text { LDL : Low Density Lipoproteins. }\end{array}$}} & $p_{1} \quad:$ & \multicolumn{5}{|c|}{ : Between no risk and one risk alleles. } \\
\hline & & & $p_{2}$ & \multicolumn{5}{|c|}{ : Between no risk and two risk alleles. } \\
\hline \multicolumn{2}{|l|}{ Creat : Creatinine. } & & $p_{3}$ & \multicolumn{5}{|c|}{ : Between one risk and two risk alleles. } \\
\hline
\end{tabular}


This table shows the baseline characteristics by allele combination as regard the patients laboratory parameters (both groups $n=88$ ).

There was significant statistical difference as regard the laboratory parameters as: Haemoglobin, cholesterol, triglycerides, HDL, LDL, creatinine, eGFR, and albumin/creatinine ratio.

\section{On performing the Post-Hoc test:}

There was significant statistical difference between no risk and one risk alleles $\left(p_{1}\right)$ as regarding: Triglycerides and HDL and between no risk alleles and two risk alleles $\left(p_{2}\right)$ as regard to cholesterol, triglycerides, HDL, LDL and detween one risk allele and two risk allele ( $p 3)$ as regard to haemoglobin, cholesterol, triglycerides, HDL, LDL, creatinine, eGFR and albumin/creatinine ratio.

Table (12): Binary logistic regression of the effect of APOL1 risk variants on $\mathrm{HTN}$-attributed nephropathy.

\begin{tabular}{lccc}
\hline & B & Sig. & Odds ratio \\
\hline G1 rs73885319 (AG/GG) & 2.861 & 0.007 & 17.486 \\
G1 rs60910145 (TG/GG) & 2.597 & 0.014 & 13.421 \\
G2 rs71785313 (ID/DD) & 2.402 & 0.024 & 11.050 \\
\hline
\end{tabular}

This table shows the binary logistic regression of the effect of APOL 1 risk variants on HTNattributed nephropathy.

For G1 rs73885319 (AG/GG): B=2.861 and Odds ratio $=17.486$. In other words: Hypertensive patients carrying AG or GG genotypes have increased risk to develop HTN-attributed nephropathy of about 17.486 times than hypertensive patients carrying none of these risk varients.

For G1 rs60910145 (TG/GG): $B=2.597$ and Odds ratio $=13.421$. In other words: Hypertensive patients carrying TG or GG genotypes have increased risk to develop HTN-attributed nephropathy of about 13.421 times than hypertensive patients carrying none of these risk varients.

For $\mathrm{G} 2$ rs71785313 (ID/DD): $\mathrm{B}=2.402$ and Odds ratio $=11.050$. In other words: Hypertensive patients carrying ID or DD genotypes have increased risk to develop HTN-attributed nephropathy of about 11.050 times than hypertensive patients carrying none of these risk varients.

\section{Discussion}

The association between Apolipoprotein L1 gene (APOL 1) variants and non-diabetic Chronic Kidney Disease (CKD) has dramatically altered the landscape in nephrology $[\mathbf{7 , 8}]$.
It is notable that in recent reports of controlled trials in African-Americans hypertension with kidney disease is associated with the APOL1 risk genotype, and kidney disease deterioration is not ameliorating by more intensive blood pressure control [9]

To our knowledge, no data are available about the association between APOL 1 gene variation and the occurrence of nephroscelerosis among Egyptian hypertensive patients so the aim of this work was to study the influence of the APOL1 gene variants (G1 and G2) on the hypertensive induced kidney disease among Egyptian Patients.

Our study proved that advanced age, male gender, longstanding hypertension, severe hypertension, low socioeconomic status, a history of cigarette smoking, increased body mass index are not risk factors for the development of hypertensive nephroscerosis which is not consistent with the study of Perry et al., (1995) [12] who proved that advanced age, male gender, longstanding hypertension, low socioeconomic status, a history of cigarette smoking, severe hypertension are risk factors for the development of hypertensive nephroscerosis. This may be due to small sample size of our study ( 88 patients) in addition that we intended matching between group 1 (hyperttensive patients with normal kidney function) and group 2 (hyperttensive patients with impaired kidney function) as regard the demographic data to elucidate the influence of APOL 1 gene G 1 and G2 risk variants on the development of hyperttensive nephroscerosis in the absence of other risk factors.

Norris et al., [13] reported that dyslipidemia is a common finding in patients with hypertensive nephrosclerosis. Several lines of evidence implicate this as a risk factor for chronic kidney disease. In the ARIC study, hypertriglyceridemia and low plasma levels of High-Density Lipoprotein (HDL) were associated with the onset of hypertensive renal disease. Hypercholesterolemia was associated with the development of ESRD in the MRFIT study; our results come in line with these results.

In a cohort by Agodoa et al., [14] of 77 patients with hypertensive nephrosclerosis, demonstrated that, as compared to those with a urinary protein excretion $<500 \mathrm{mg} /$ day, patients with a higher daily urinary protein excretion exhibited a significantly faster rate of decline in GFR. Similarly, patients with a urine protein/creatinine ratio $>0.22$ enrolled in the African American Study of Kidney Disease and Hypertension (AASK) exhibited a two-fold higher rate of decline in GFR as compared with 
those with lower protein excretion rates; our results are consistent with these results.

In our study there was significant statistical difference between the two studied groups as regard the frequency of the APOL1 G1 and G2 risk variants; which are more frequent in group 2 and this come in line with $[7,8]$ who reported that APOL 1 G1 and G2 risk variants are highly associated with non-diabetic forms of kidney disease in particular hypertensive nephropathy.

More recent studies suggest that the presence of two risk alleles (termed G1 and G2) in any combination (G1/G1, G1/G2, G2/G2) in the last exon of gene encoding Apolipoprotein-L 1 (APOL 1) are associated with 5-29 times higher odds of severe kidney disease, including non-diabetic ES$\mathrm{RD}$, hypertension-related ESRD, focal segmental glomerulo sclerosis, and HIV-related nephropathy [15].

In the large community-based study of 15,792 adults recruited from four US communities (subanalysis of ARIC Study), participants carrying two risk alleles were at an increased risk of developing incident CKD as well as ESRD events in comparison to patients lacking these alleles or having only one of them [16].

Moreover, over $31 \%$ of African American CKD carriers of two APOL1 risk alleles progressed to ESRD, while only $13 \%$ of patients with CKD and with zero or one risk allele faced such aggravation of renal function during over 6 years of followup. Quite high prevalence of G1 and G2 risk alleles among African Americans in comparison to Americans with European ancestry could be one of reasons for the increased kidney disease burden in African Americans. In the Dallas Heart Study including 1776 African Americans, carriers of two APOL 1 risk alleles had three- to four-fold increased odds of prevalent microalbuminuria and reduced estimated GFR (eGFR; eGFR $<60 \mathrm{~mL} / \mathrm{min}$ per $1.73 \mathrm{~m}^{2}$ ) in comparison with participants with zero or one risk allele. This relationship was influenced by diabetes status [16].

Our results come in line with these studies as our study proved that most patients with hypertensive nephroscelerosis (Group II) carry two risk alleles and showed more decline in eGFR than Group I despite matching in the hypertension duration and severity.

Compared with European Americans, blacks have an increased burden of albuminuria and progressive CKD [17]. Although much of this risk difference is explained by an increased prevalence of hypertension, diabetes mellitus, and obesity among blacks as well as racial disparities in access to care [18], the $\mathrm{G} 1$ and $\mathrm{G} 2$ variants in the gene encoding Apolipoprotein L 1 (APOL 1) likely also contribute [7]. Studies to date have demonstrated that blacks with the APOL 1 high-risk genotypes (2 risk alleles) have a 2-to 20 -fold higher risk for various forms of kidney disease compared with those with the low-risk genotypes (0-1 risk alleles) [9].

In a community-based study, however, the distribution of annual eGFR decline among APOL1 high-versus low-risk individuals substantially overlapped [19]. Even among blacks with established CKD, a notable proportion of individuals with the high-risk genotypes had stable kidney function over long-term follow-up [20] .

Our study proved that hypertensive patients possessing APOL-1 risk variants have increased incidence to develop proteinuria and renal impairment than hypertensive patients possessing none of these variants.

\section{Conclusion:}

APOL1 G1 rs73885319, G1 rs60910195 and G2 rs71785313 gene polymorphism is associated with increased risk of hypertensive induced kidney disease among Egyptian Patients. Most patients with hypertensive nephroscelerosis (Group II) showed more decline in e-GFR than Group I despite matching in the hypertension duration and severity.

\section{References}

1- D'AGATI V.D., KASKEL F.J. and FALK R.J.: Focal segmental glomerulosclerosis. N. Engl. J. Med., 365 (25): 2398-411, 2011.

2- ROSSET S., TZUR S., BEHAR D.M., WASSER W.G. and SKORECKI K.: The population genetics of chronic kidney disease: Insights from the MYH9-APOL1 locus. Nat. Rev. Nephrol., 7 (6): 313-26, 2011.

3- TWAGIRUMUKIZA M., De BACQUER D., KIPS J.G., De BACKER G., STICHELE R.V. and VAN BORTEL L.M.: Current and projected prevalence of arterial hypertension in sub-Saharan Africa by sex, age and habitat: An estimate from population studies. J. Hypertens, 29 (7): 1243-52, 2011.

4- IBRAHIM M.M., RIZK H., APPEL L.J., EL AROUSSY W., HELMY S., SHARAF Y. and WHELTON P.K.: Hypertension prevalence, awareness, treatment, and control in Egypt. Results from the Egyptian National Hypertension Project (NHP). NHP Investigative Team. Hypertension, 26 (6 Pt 1): 886-90, 1995.

5- VOLHARD F. and FAHR T.: Bright's kidney diseaseclinic Pathology and Atlas, Berlin, Springer 1914. (Cited 
from: The scientific Journal Facta Universitatis Series: Medicine and Biology Vol. 5, No. 1, pp. 1-5), 1998.

6- TOLINS J.P., SHULTZ P. and RAIJ L.: Mechanisms of hypertensive glomerular injury. Am. J. Cardiol., 62: 54G58G, 1988.

7- GENOVESE G., FRIEDMAN D.J., ROSS M.D., et al.: Association of trypanolytic ApoL1 variants with kidney disease in African Americans. Science, 329: 841-5, 2010.

8- TZUR S., ROSSET S., SHEMER R., et al.: Missense mutations in the APOL1 gene are highly associated with end stage kidney disease risk previously attributed to the MYH9 gene. Hum. Genet., 128 (3): 345-50, 2010.

9- LIPKOWITZ M.S., FREEDMAN B.I., LANGEFELD C.D., et al.: Apolipoprotein L1 gene variants associate with hypertension-attributed nephropathy and the rate of kidney function decline in African Americans. Kidney Int., 83: 114-20, 2013.

10- IZZO J.L., Jr. and BLACK H.R.: Hypertension primer: The Essentials of High Blood Pressure. Council on High Blood Pressure Research, American Heart Association; Dallas, TX: p. 3, 1993.

11- KALKAN G., YIGIT S., KARAKUS N., BAS Y., et al.: Association between interleukin 4 gene intron 3 VNTR polymorphism and recurrent aphthous stomatitis in a cohort of Turkish patients. Gene, 527: 207-10, 2013.

12- PERRYHM J.R., MILLER J.P., FORNOFF J.R., et al.: Early predictors of 15-year end-stage renal disease in hypertensive patients. Hypertension, 25: 587-94, 1995.

13- NORRIC K.C., HORNHILL-JOYNES M., ROBINSON C., et al.: Cocaine use, hypertension, and end-stage renal disease.Am. J. Kidney Dis., 38: 523-8, 2001.
14- AGODOA L.Y.: For the African American Study of Kidney Disease and Hypertension (AASK) Study Group. Effect of ramipril Vs. amlodipine on renal outcomes in hypertensive nephrosclerosis: A randomized controlled trial. JAMA, Vol. 6, No. 285, Issue 21, (June), pp. 271928, 2001.

15- FOSTER M.C., CORESH J., FORNAGE M., ASTOR B.C., GRAMS M., FRANCESCHINI N., BOERWINKLE E., PAREKH R.S. and KAO W.H.: APOL1 Variants Associate with Increased Risk of CKD among African Americans. JASN, 24: 1484-91, 2013.

16- FRIEDMAN D.J., KOZLITINA J., GENOVESE G., JOG P. and POLLAK M.R.: Population-based risk assessment of APOL1 on renal disease. J. Am. Soc. Nephrol., 22: 2098-105, 2011.

17- PERALTA C.A., BIBBINS-DOMINGO K., VITTINGHOFF E., LIN F., FORNAGE M., KOPP J.B. and WINKLER C.A.: APOL1 genotype and race differences in incident albuminuria and renal function decline. J. Am. Soc. Nephrol., 27: 887-93, 2016.

18- CREWS D.C., CHARLES R.F., EVANS M.K., ZONDERMAN A.B. and POWE N.R.: Poverty, race, and CKD in a racially and socioeconomically diverse urban population. Am. J. Kidney Dis., 55: 992-1000, 2010.

19- GRAMS M.E., REBHOLZ C.M., CHEN Y., RAWLINGS A.M., ESTRELLA M.M., SELVIN E., APPEL L.J., TIN A. and CORESH J.: Race, APOL1 risk, and eGFR decline in the general population. J. Am. Soc. Nephrol., 27: 284250, 2016.

20- TIN A., GRAMS M.E., ESTRELLA M., LIPKOWITZ M., GREENE T.H., KAO W.H., LI L. and APPEL L.J.: Patterns of kidney function decline associated with APOL1 genotypes: Results from AASK. Clin. J. Am. Soc. Nephrol., 11: 1353-9, 2016. 


\section{التعدد الشكلى لجين الآبولايبوبروتين-1 فى مرضى تصلب الكلى المصريين الناتج عن إرتفاع ضغولين في الدم مرضم}

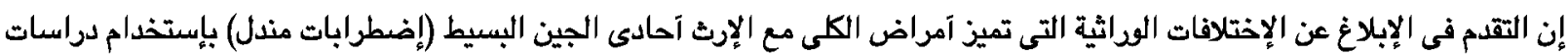

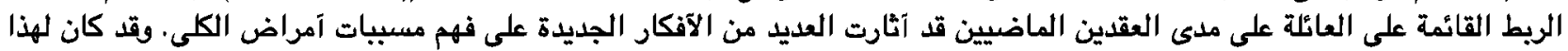

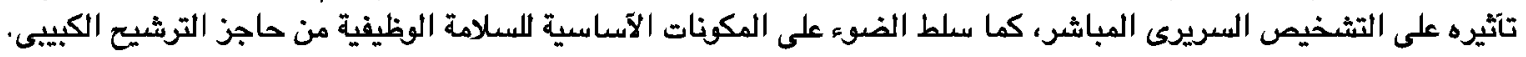
يمثل إرتفاع ضغط الدم الشريانى مشكلة صحية عامة رئيسية في المجتمعات الغربية ولا سيما لعلاقته القوية مع معدلات إعتلال ووفيات القلب والآوعية الدموية.

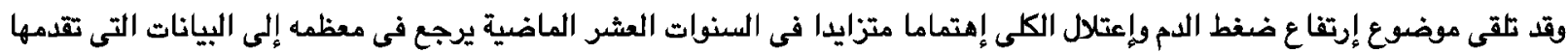

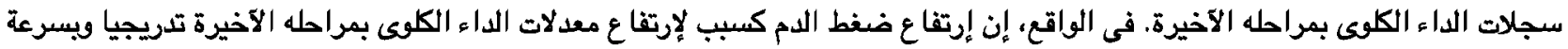
يعد آكبر من جميع الآسباب الآخرى (بإستثناء مرض الآيرة السكرى) في آمريكا الشمالية وآورويا.

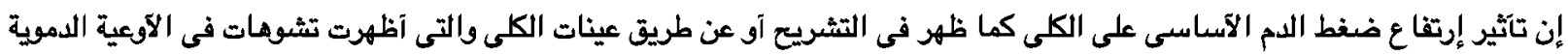

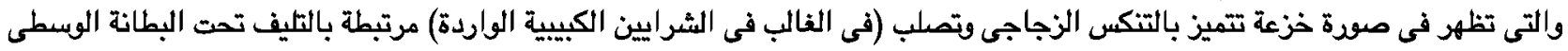

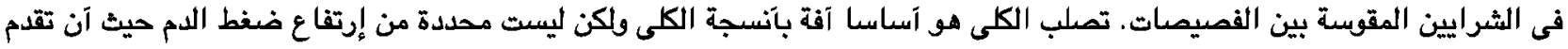
السن قد يحرض تثوهات مماثلة في الكلى.

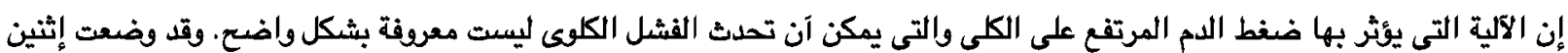

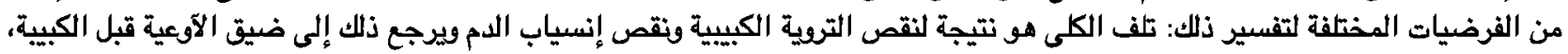

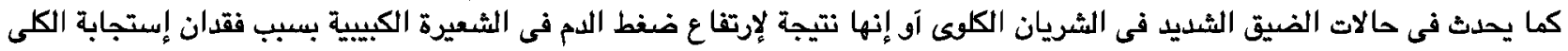

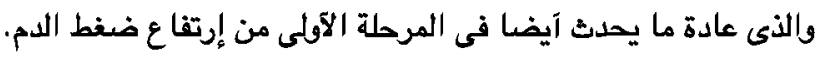

إن العلاقة بين متغيرات جين الآبولايبوبروتين-1 ومرض الكلى المزمن الفير سكرى غيرت بشكل كبير في علاج آمراض الكلى.

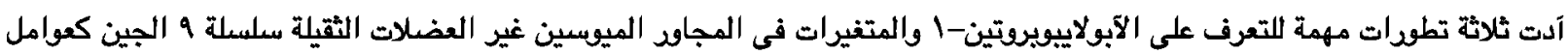

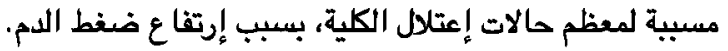

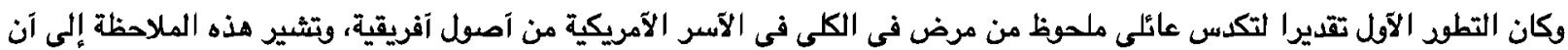

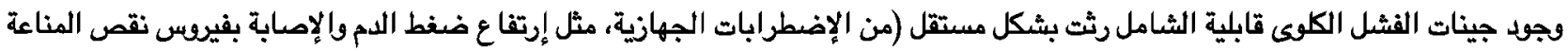

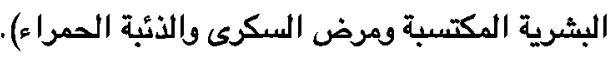

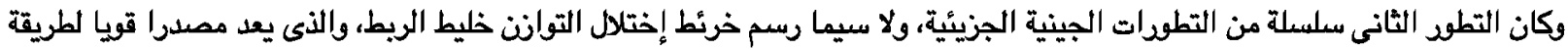

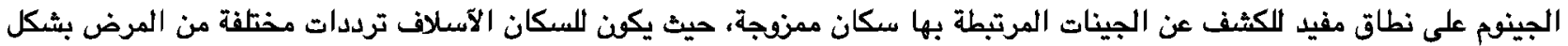

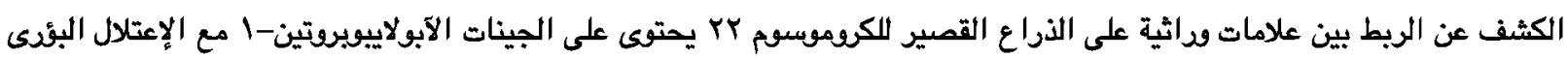

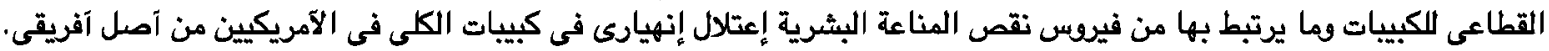

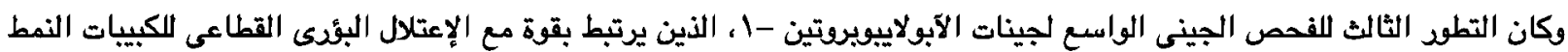

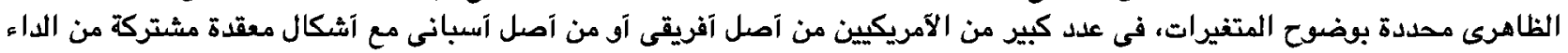
الكلىى بمراحله الآخيرة.

هذه التطودات متتابعة آدت إلى إدراك آن الإعتلال البؤرى القطاعى اللكيبيات وإعتلال الكلية المرتبطة بفيروس نقص المناعة البشرية المكسبة،

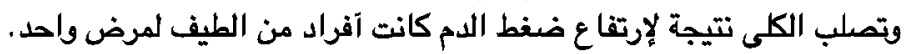

على حد علمنا، لا توجد بيانات متاحة عن العلاقة بين التعدد الشكلى لجين الآبولاييويروتين-1 وحدوث تصلب الكلى بين المرضى المصريين المصابين بإرتفاع ضغط الدم الآولى.

الهدف من البحث: دراسة تآثير التعدد الشكلى لجين الآبولايوبروتين-1 على حدوث تصلب الكلى بين المرضى المصريين المصابين بإرتفاع ضغط الدم الآولىى. 